\title{
Demographic change and the European income distribution
}

\section{Mathias Dolls ${ }^{1,2} \cdot$ Karina Doorley,3 (D) Alari Paulus ${ }^{4} \cdot$ Hilmar Schneider $^{2}$. Eric Sommer ${ }^{2}$}

Received: 28 March 2018 / Accepted: 26 February 2019 / Published online: 14 May 2019

(C) The Author(s) 2019

\begin{abstract}
This paper assesses the effect of key demographic changes (population ageing and increasing educational attainment) that are expected by 2030 on the income distribution in the EU-27 and examines the potential of tax-benefit systems to counterbalance negative developments. Theory predicts that population ageing should increase income inequality, while the effect of upskilling is more ambiguous. Tax-benefit systems may stabilize these expected changes though this is largely an empirical question given their typically complex nature. We use a decomposition technique to isolate the effect of projected demographic change on income inequality and poverty from the reaction of the labor market to this demographic change through wage adjustments. Our results show that demographic change is likely to lead to increasing inequality while related wage adjustments work mainly in the opposite direction. Changes to projected relative poverty are minimal for most countries. With a few exceptions, EU tax-benefit systems are able to absorb most of projected increase in market income inequality.
\end{abstract}

Keywords Income distribution · Demography $\cdot$ Labor market · Decomposition

\section{Introduction}

The labor markets and public finances of EU member states are facing serious challenges from expected demographic changes over the course of the next few decades. Two longterm trends — population ageing and upskilling — increasingly contribute to employment

Electronic supplementary material The online version of this article (https://doi.org/10.1007/s10888-019-09411-z) contains supplementary material, which is available to authorized users.

Karina Doorley

karina.doorley@esri.ie

1 Ifo Institute, Munich, Germany

2 IZA Bonn, Bonn, Germany

3 ESRI Dublin, Whitaker Square, Sir John Rogerson's Quay, Dublin 2, Dublin, Ireland

4 ISER, University of Essex, Colchester, England 
dynamics (OECD 2014, p.20). These will also shape household income distributions and are likely to have profound effects on income inequalities and poverty levels. Inequality and, to a lesser extent, relative poverty have been increasing in most OECD countries from the mid-1980s to the Great Recession (Tóth 2014).

Several theoretical studies have shown that a larger share of older people tends to increase overall income inequality (e.g von Weizsäcker 1988, 1995; Deaton 1997). This is for several reasons. According to life cycle theory, within-cohort earnings inequality increases as cohort members get older due to the cumulative effect of different levels of human capital investment and learning abilities on incomes over the life course. The ageing of the workforce alone, therefore, results in less equally distributed (cross-sectional) earnings. A greater share of retired people increases population income inequality further due to the fact that retirees have lower incomes compared to workers. An increased proportion of pensioners also puts the public provision of pensions under pressure, more so if productivity growth is not sufficient to compensate for a shrinking workforce. ${ }^{1}$ Further interaction effects with labor markets as a shrinking working population, other things being equal, is likely to put upward pressures on wage levels. A call by von Weizsäcker (1996) for more theoretical and, in particular, empirical research on the distributional implications of ageing appears still valid today.

Upskilling will also lead to an increase in average earnings, provided that the larger supply of better educated workers can be absorbed by the economy. ${ }^{2}$ The effect of skill upgrading on earnings inequality, however, is ambiguous, depending on the dynamics of the high-skilled wage premium, among other factors. (Atkinson and Bourguignon 2015). However, the empirical evidence for the OECD and EU countries to date indicates that upskilling has not led to increased wage inequality over the last few decades (Förster and Tóth 2015, p.1801).

There are few other studies which make projections about future labor markets and/or income distributions. Aziz et al. (2015) use demographic projections combined with a reweighting approach to analyze the effect of demographic change on income distributions in New Zealand in 2010-2060 but abstract from any related wage changes. Their results point to a small increase in market income inequality, while the inequality of disposable income is stable or decreasing (depending on the measure). They also show that overall and child poverty rates can be expected to decrease by up to 5 percentage points. This illustrates the redistributive capacity of the tax-benefit system in New Zealand. Edwards and Lange (2013) model the US labor force in 2030 and show how returns to education as well as the gender wage gap will be affected by demographic change. Their key finding is that the trend in demand towards more skilled (female) labor will continue to outstrip supply despite rapid increases in the latter. This will lead to a continuation of the increase in the wage skill premium.

The relevance of population ageing and upskilling is likely to be different across countries (OECD 2014), which, given theoretical ambiguities, highlights the importance of (comparative) empirical work. It is even more important to anticipate such influences at an early stage, in the context of distributional targets such as Europe-2020 (European Commission 2010).

This study builds on Dolls et al. (2017), which studies the effect of demographic changes between 2010 and 2030 on labor force participation and government budgets. In this paper,

\footnotetext{
${ }^{1}$ von Weizsäcker (1995) also demonstrates that considering the type of funding arrangements and reactions to avoid fiscal deficits can introduce some ambiguity regarding the effect of ageing on the income distribution. ${ }^{2}$ CEDEFOP (2012) forecasts for 2020 show trends towards more skill-intensive jobs together with upskilling, though with scope for mismatches.
} 
we go beyond fiscal measures and assess how income distributions in the EU are likely to be affected by future demographic changes such as population ageing and upskilling. We examine the potential of current tax-benefit systems in the EU-27 to cope with such changes, showing the implications of each tax-benefit system for future poverty and inequality.

Our study is related to that of Aziz et al. (2015) for New Zealand in that we employ reweighting and microsimulation techniques to account for projected demographic changes between 2010 and 2030. We extend their method by also modeling labor market reactions to these population changes through wage adjustments, and assess their combined effect on the income distribution of the EU-27. To the best of our knowledge, no study has attempted this before.

We also show the effect of demographic change separately from the effect of wage adjustment to this demographic change, drawing on the approach of Bargain and Callan (2010) to decompose changes in the income distribution. The microsimulation method (Bourguignon and Spadaro 2006) allows us to simulate projected demographic changes and model wage reactions, and, by holding everything else constant, to isolate their respective impacts.

We rely on two sets of demographic and skills projections, an optimistic and a pessimistic scenario, from Huisman et al. (2013) which make different assumptions about fertility, life-expectancy, educational attainment, migration and household formation. The two main trends driving changes in the composition of the work force are population ageing and the upskilling of the population. Our method of constructing future income distributions involves, in the first stage, reweighting to make currently observed household-level data reflect future population structures. In the second stage, we obtain new partial labormarket equilibrium wage levels by combining changes in the work force resulting from demographic changes with existing detailed estimates of labor demand and labor supply elasticities in the literature. To calculate household disposable incomes, we employ EUROMOD - the EU tax-benefit microsimulation model - which uses EU-SILC data on household demographic and labor market characteristics as well as market incomes for nationally representative samples of households as input.

Our results suggest that demographic change is likely to lead to increasing income inequality while related wage adjustments tend to work in the opposite direction. The combined effect results in a modest increase in income inequality in the EU as a whole, although cross-country differences in this effect can be expected. We also find that inequality is more likely to increase in countries which currently have relatively low inequality levels, potentially leading to a convergence in inequalities at the EU level. Results for relative poverty are more ambiguous with most countries experiencing little or no change in relative poverty. However, for some countries, policy changes may be needed to keep poverty and inequality at acceptable levels.

The paper is structured as follows. Section 2 explains the methodology: how demographic projections were obtained and linked with the income distribution, the framework for estimating adjustments in the labor market through labor supply and demand responses and the decomposition method to assess the effects of demographic change on the income distribution. Section 3 discusses the main demographic trends and the new equilibrium in the future labor market. Section 4 presents our findings on how these developments affect the income distributions in the EU countries. Section 5 discusses the stabilizing properties of tax-benefit systems in the EU-27. Section 6 concludes. 


\section{Data and methodology}

\subsection{Tax-benefit calculator}

We use EUROMOD as a basis for our analysis. EUROMOD is a static tax-benefit calculator for the EU countries, which allows for comparative analysis of tax-benefit systems and their impact on the income distribution in a consistent way through a common framework (Sutherland and Figari 2013). Based on a representative sample of households of with information about their socio-demographic and labor market characteristics as well as market incomes (e.g. earnings), EUROMOD simulates disposable income for each household by applying a set of tax-benefit rules. The latter can refer to existing tax-benefit systems or (user-specified) reform scenarios. EUROMOD has become a heavily applied tool in inequality research. ${ }^{3}$

EUROMOD input-data are mainly based on the European Union Statistics on Income and Living Conditions (EU-SILC) released by Eurostat, or its national counterparts, where available and when they provide more detailed information. Each country component of the model is thoroughly validated with results documented in a Country Report. ${ }^{4}$

We use version F6.0 of EUROMOD with input datasets based primarily on the SILC 2008 wave (2007 wave is used for France and 2009 wave for Malta) and the Family Resources Survey 2008/09 for the UK. The sample size for each country varies from about 10 thousand individuals for Luxembourg and Cyprus to more than 50 thousand individuals for Italy and the UK.

Our analysis focuses on changes in the distribution of household disposable income, equivalised to account for household size and composition by using the modified OECD equivalence scale. Disposable income, as widely used to measure poverty and inequality, is defined as all household incomes net of taxes and social contributions and after the receipt of all types of cash benefits. Household market income (or original income) refers to the total amount of labor income (excluding employer social insurance contributions), capital income, private pensions and private transfers, i.e. income before taxes and benefits.

\subsection{Projections and reweighting}

We rely on the Netherlands Interdisciplinary Demographic Institute's (NIDI) demographic projections (Huisman et al. 2013) to adjust our micro data such that they reflect population characteristics of the year 2030 (similar to Dolls et al. 2017). Huisman et al. (2013) take Eurostat's EUROPOP2010 projections for the key demographic determinants (fertility rate, mortality rate, level of net migration) as a reference point (European Commission 2012) and develop two different scenarios which are labeled as 'tough' and 'friendly'. In addition to the EUROPOP2010 projections, the scenarios are based on assumptions about internal (rural-urban) migration (ESPON \& NIDI 2010) and educational attainment (KC et al. 2010). They can be seen as upper and lower bounds of the severity of demographic change. Both scenarios predict that ageing will be the main demographic trend in the next decades leading to lower growth rates of the working age population and higher dependency ratios, with the tough scenario reflecting more pessimistic assumptions about demographic developments

\footnotetext{
${ }^{3}$ For recent examples, see Bargain et al. (2017), Figari et al. (2017), Paulus et al. (2017).

${ }^{4}$ See https://www.euromod.ac.uk/using-euromod/country-reports.
} 
Table 1 Assumptions underlying the population scenarios

\begin{tabular}{llc}
\hline & $\begin{array}{l}\text { Scenario } \\
\text { tough }\end{array}$ & friendly \\
\hline International migration & low & high \\
Rural-to-urban migration & high & low \\
Fertility & low & high \\
Increase in life expectancy & low & high \\
Educational attainment & low & high \\
\hline
\end{tabular}

See Huisman et al. (2013) for more details on the demographic projections. Their tables 1-4 show for each of the key demographic determinants (fertility rate, life expectancy, net migration) and for each EU-27 member state the last observation, the EUROPOP2010 projection for the year 2030 as well as the projections in the tough and friendly scenario, respectively. For most (but not all) EU-27 countries, projections in the tough (friendly) scenario are above (below) the EUROPOP2010 projection. Differences in the degree of urbanisation are small between the two scenarios. For the level of educational attainment, KC et al. (2010)'s 'constant enrolment' ('fast track') scenario is chosen in the tough (friendly) scenario. The tough (friendly) scenario assumes a stagnation (an increase) in educational attainment

and greater challenges for European policy makers. Table 1 provides a short overview of the main features of both scenarios.

The demographic projections include joint distributions of age, sex, level of educational attainment and household position for the EU-27 until 2030. ${ }^{5}$ We incorporate these projections into our representative European household micro data by a reweighting procedure. ${ }^{6}$ Our baseline micro data contain personal weights for each individual in our sample in order to adjust for sample design and/or differential nonresponse. Every country data set is thus representative for the respective population in the base year (i.e. 2008). In a first step, we alter the weights such that they reflect the population size and structure in 2010, keeping labor market conditions constant.

This ensures that changes in population characteristics between 2010 and 2030 are solely due to the underlying population scenarios and not caused by potential inconsistencies between our country-level data sources. In a second step, we reweight the 2010 samples such that they precisely reflect the characteristics of each EU population in terms of age, educational attainment and household structure as projected for the year $2030 .^{7}$

\footnotetext{
${ }^{5} \mathrm{~A}$ cohort component model is used to project the age and sex distribution while education projections are based on $\mathrm{KC}$ et al. (2010). A comparison of the NIDI population projections by skill level to those of the European Centre for the Development of Vocational Training (Cedefop), which provides an EU-wide population projection for 2020, shows that the two are well aligned in terms of headcounts (CEDEFOP 2012). ${ }^{6}$ Cf. Deville and Särndal (1992) and DiNardo et al. (1996). For an application of sample reweighting in the context of tax-benefit microsimulation, see Cai et al. (2006). For applications of reweighting techniques in a different context - modeling an increase in unemployment - see Immervoll et al. (2006) and Dolls et al. (2012).

${ }^{7}$ The household position is differentiated between singles, single parents, children living at home, couples without children, couples with children and other. Our analysis concentrates on differences between 2010 and 2030 and ignores intermediate developments.
} 


\subsection{Linking labor supply and demand}

Our implementation of the supply-demand link (described in more detail in Dolls et al. 2017) defines twelve distinct labor markets in each country, differentiated by marital status, gender, and skill level. This ensures a flexible adjustment process as it incorporates the main sources of heterogeneous labor market behavior. Aggregate labor supply is modeled using a rich set of intensive and extensive labor supply elasticities from Bargain et al. (2014) along these dimensions. The elasticities account for the fixed costs of work, labor market restrictions within countries or even states, preference heterogeneity with respect to age, the presence and number of children as well as unobserved heterogeneity components. Table 3 reports aggregated (total) gross wage labor supply elasticities for the different country groups.

While estimates for males in couples are very similar across country groups and skill levels (mostly just under 0.1), elasticities for other population groups range from about 0.1 to 0.5 (reaching even 0.65 for single males).

Differences between skill groups are more pronounced for single males and females with low-skilled workers having the highest labor supply elasticities, followed by high-skilled workers, while those with medium skills have the lowest elasticities. Men tend to be slightly more responsive on the extensive margin, the opposite holds for women. Overall, elasticities for the Eastern European countries are among the lowest, while those for the Anglo-Saxon and Southern country groups are among the highest.

The demand side is modelled using wage elasticities obtained from the meta-regression analysis in Lichter et al. (2015). They account for differences in skills, labor market institutions as well as the importance of specific sectors across countries. The variation within countries comes from skill differences leading us to two labor demand elasticities per country grouping (high/medium skilled vs low skilled), as reported in the lower part of Table 3. By means of the linear-time trend in the meta-analysis, these elasticities are extrapolated to 2030 . This reflects the decreasing trend in labor demand responsiveness which is possibly a consequence of technological change. The resulting demand elasticities for 2030 are highest for the Eastern and Anglo-Saxon countries (-0.7 to -0.9). Eastern European countries tend to have less strict laws concerning hiring and separations and this causes lower adjustment costs for firms and may increase incentives to adjust labor demand in response to wage changes. Demand elasticities for the other country/skill groups range between -0.5 and -0.6 , and are generally higher for the low-skilled.

Figure 1 illustrates the basic mechanism of our supply-demand-link. Starting from the equilibrium point $A$ in 2010, a decrease in the labor force due to demographic trends (as is observed in many EU countries between 2010 and 2030), shifts the aggregate supply curve to the left. ${ }^{8}$ In the absence of demand-side adjustments, the new equilibrium would be at point $B$, resulting in a higher wage due to the higher scarcity of labor. A demand shift can be expected due to the changing size of the population. As the population is projected to change, the demand for goods and services can be expected to change accordingly, leading to a lower or a higher demand for labor. This is represented, in the example in Fig. 1, by a downward shift of the demand curve which moves the equilibrium point $B$ to $C$. Point $C$ denotes wage and employment level in the equilibrium. The resulting relative change in market wages $\frac{w_{1}}{w_{0}}$ is fed back into the micro-data to obtain counterfactual individual earnings

\footnotetext{
${ }^{8}$ Under the assumption of constant elasticities, any supply/demand curve can be fully characterized by the elasticity and a single observed point of hours.
} 


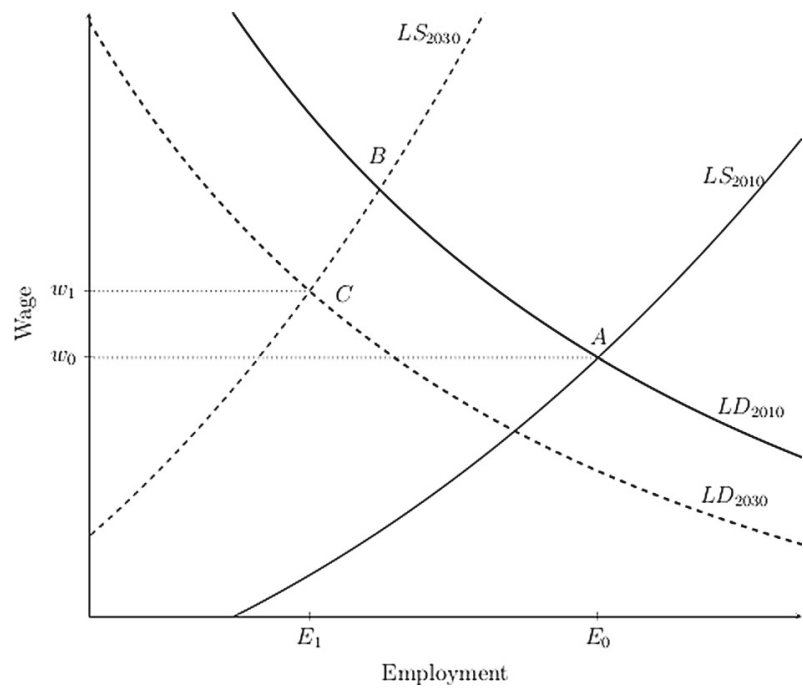

Fig. 1 Linking labor supply and demand. Source: Dolls et al. (2017). Notes: The figure shows an example in which both the labor force and the population shrink between 2010 and 2030

for $2030 .^{9}$ These are converted into counterfactual disposable incomes. In order to account for different responses depending on the worker type, this procedure is carried out separately for the 12 combinations of gender, couple status and skill level within each country. As the underlying elasticities are estimated on employees only, earnings of dependent workers is the only income component altered here. Self-employed wages are hence held constant, as well as income from rents or capital.

\subsection{The decomposition method}

We follow the decomposition framework in Bargain and Callan (2010) to decompose changes in the income distribution. Their original application examined historic changes in the income distributions in France and Ireland. Further studies have applied it in the analysis of changes in income distributions in the UK (Bargain 2012a, b); in the US (Bargain et al. 2015) and comparatively for a selection of European countries (Bargain et al. 2017; Hills et al. 2019; Paulus et al. 2017). Our paper provides the first application of this method to future income distributions and covers the whole EU-27.

Denote $y$ a matrix with household socio-demographic characteristics and market income sources (with each row describing a single household). Let $d$ denote the 'tax-benefit function' which calculates household disposable income on the basis of household characteristics, pre-tax and transfer incomes, and a set of tax-benefit policy parameters with

\footnotetext{
${ }^{9}$ On the individual level, labor market adjustments are obtained in a two-step procedure. First, for employed persons, the change in weekly hours is calculated from the intensive labor supply elasticity. In a second step, the extensive elasticity defines a counterfactual employment rate for this group. To meet this new employment rate, employable group members' employment status is changed subsequently until the new employment rate is met. The number of weekly hours for new labor market entrants (in case of an increasing employment rate) is determined by the average amount of employed persons sharing the same gender, couple status and skill level.
} 
monetary values $p$ (e.g., tax brackets, benefit amounts). We can then express the distribution of disposable income for the population of year $k$, under the tax-benefit structure of year $i$ and the tax-benefit parameters of year $j$ as $d_{i}\left(p_{j}, y_{k}\right)$. We will be focusing on distributional indices $I$ (e.g. inequality, poverty), computed as a function of the (simulated) distribution of disposable income, i.e. $I\left[d_{i}\left(p_{j}, y_{k}\right)\right]$. The total change in a given distributional index between two time periods, $t=0$ (e.g. 2010) and $t=1$ (e.g. 2030), can be written as

$$
\Delta I=I\left[d_{1}\left(p_{1}, y_{1}\right)\right]-I\left[d_{0}\left(p_{0}, y_{0}\right)\right]
$$

This can be decomposed into a (direct) policy effect and changes in population characteristics (including market incomes), using a (simulated) counterfactual income distribution $d_{0}\left(\alpha p_{0}, y_{1}\right)$ and $\alpha$ to adjust the nominal levels of policy parameters with monetary values. ${ }^{10}$

$$
\Delta I=\underbrace{\left\{I\left[d_{1}\left(p_{1}, y_{1}\right)\right]-I\left[d_{0}\left(\alpha p_{0}, y_{1}\right)\right]\right\}}_{\text {policy effect }}+\underbrace{\left\{I\left[d_{0}\left(\alpha p_{0}, y_{1}\right)\right]-I\left[d_{0}\left(p_{0}, y_{0}\right)\right]\right\}}_{\text {changes in characteristics }}
$$

In this analysis, we consider two possible values for $\alpha$. The first, unity, reflects an approach where the two components are assessed without indexing tax-benefit policy parameters in the counterfactual scenario. More precisely, as wage adjustments presented in the next section should be interpreted in 2010 levels, the policy parameters should be understood as kept fixed in real terms for our benchmark. However, when incomes rise faster than prices, the total number of taxpayers (and the number of higher-rate taxpayers) increases. This phenomenon of bracket creep (Immervoll 2005) is likely to affect the final distribution of post-tax income. Therefore, we employ $\alpha$ equal to the change in average market income between 2010 and 2030 to measure each component against a scenario where tax-benefit policy parameters are indexed in line with developments in market income, constituting a distributionally neutral benchmark. ${ }^{11}$ In what follows, we present only results for $\alpha$ equal to this distributionally neutral factor but results for the decomposition in which $\alpha=1$ are qualitatively similar. Note that the actual total change between 2010 and 2030 can only be assessed once micro-data become available for both periods and 2030 tax-benefit policy rules are known. Here we use projected 2030 market incomes (in real terms), denoting the new population structure and market income distribution after demographic changes (alone) as $y_{d}$. After wage adjustments, the distribution in the new labor market equilibrium is denoted $y_{d w}$. We seek to quantify changes in the income distribution, on the basis of an $\alpha$ valued at the change in average market income $\left(\alpha_{d w}=\bar{y}_{d w} / \bar{y}_{0}\right)$ :

$$
\Delta I^{c}=I\left[d_{0}\left(\alpha_{d w} p_{0}, y_{d w}\right)\right]-I\left[d_{0}\left(p_{0}, y_{0}\right)\right]
$$

The last expression corresponds to the second term in Eq. 2, i.e. the effect of changes in population characteristics on the income distribution.

We decompose this further to separate a demographic effect from a wage effect. The demographic effect shows the change in the disposable income distribution, which is due to demographic change (population ageing, upskilling, etc.), while the wage effect represents the market reaction to this demographic change through labor demand (and subsequent labor supply) adjustment. Non-wage income, e.g. income from self-employment or capital, is

\footnotetext{
${ }^{10}$ Note that decomposition is path-dependent. Here we show only a version assessing policy effects conditional on the end-period data.

${ }^{11}$ Bargain and Callan (2010) argue that gross income inflation is a distributionally neutral factor that seems most appropriate for such decomposition exercises. The choice of the uprating factor is also discussed in Bargain (2012a).
} 
assumed to remain constant in real terms. Omitting subscript 0 and noting that $\alpha_{d w}=\alpha_{w} \alpha_{d}$, the decomposition is presented as follows:

$$
\begin{aligned}
& \Delta I^{c}=\left\{I\left[d\left(\alpha_{d w} p, y_{d w}\right)\right]-I\left[d\left(\alpha_{d} p, y_{d}\right)\right]\right\}+\left\{I\left[d\left(\alpha_{d} p, y_{d}\right)\right]-I[d(p, y)]\right\} \\
&= I\left[d\left(\alpha_{d w} p, y_{d w}\right)\right]-I\left[d\left(\alpha_{d w} p, \alpha_{w} y_{d}\right)\right](\text { wage effect }) \\
&+I\left[d\left(\alpha_{d w} p, \alpha_{w} y_{d}\right)\right]-I\left[d\left(\alpha_{d} p, y_{d}\right)\right](\text { income growth, } w) \\
&+I\left[d\left(\alpha_{d} p, y_{d}\right)\right]-I\left[d\left(\alpha_{d} p, \alpha_{d} y\right)\right](\text { demographic effect }) \\
&+I\left[d\left(\alpha_{d} p, \alpha_{d} y\right)\right]-I[d(p, y)](\text { income growth, } d)
\end{aligned}
$$

Altogether there are five different simulated income distributions. $d(p, y)$ is simply the distribution of disposable income in 2010. ${ }^{12} d\left(\alpha_{d} p, y_{d}\right)$ and $d\left(\alpha_{d w} p, y_{d w}\right)$ correspond to the distribution of disposable income after demographic changes, and, respectively, before and after subsequent wage adjustments. Policy parameters with monetary values are adjusted with $\alpha_{d}$ and $\alpha_{d w}=\alpha_{w} \alpha_{d}$, respectively, to keep them in line with projected market income changes. Finally, $d\left(\alpha_{d} p, \alpha_{d} y\right)$ and $d\left(\alpha_{d w} p, \alpha_{w} y_{d}\right)$, which are used to capture changes in average income levels, are constructed on the basis of the 2010 distribution and the 2030 distribution (without wage adjustments), respectively, scaling both market incomes and monetary parameters (with $\alpha_{d}$ and $\alpha_{w}$, respectively). That is, $\alpha_{d} y$ retains the structural characteristics of the base year data (in particular, the distribution of market income) but adopts the average income levels prevailing after demographic changes (and before wage adjustments). In contrast, $\alpha_{w} y_{d}$ retains the structural characteristics of population after demographic changes (and before wage adjustments) but adopts the income levels prevailing after wage adjustments. It is worth pointing out again that generally one ought to consider alternative ordering of components. However, this is not meaningful in our case as there are no wage responses to demographic changes to consider before the latter are imposed.

As tax-benefit functions, $d(p, y)$, are usually linearly homogeneous in $p$ and $y$, a simultaneous change in nominal levels of both market incomes and monetary tax-benefit parameters should not affect the relative position of households in the distribution of disposable income. The direct consequence of this is that the terms above capturing nominal changes (the income growth effects) are approximately zero for scale-invariant distributional indices ${ }^{13}$ and we are left with two components: wage effect and demographic effect. Furthermore, given this approximation, we can estimate the two effects with equation (4), which is technically easier to implement.

\section{0 population projections}

\subsection{Demographic changes}

Table 4 describes projected changes to the population between 2010 and 2030 . We see that the total EU population in 2030 is projected to slightly decrease in the tough scenario $(-3 \%)$

\footnotetext{
${ }^{12}$ As the income reference period for the input datasets is either 2007 or 2009, market incomes have first been updated to 2010 levels using appropriate factors for each income source, which reflect growth in their average values.

${ }^{13}$ This has been empirically checked for a number of European countries in Bargain and Callan (2010) and Bargain et al. (2017)
} 
and to increase in the friendly scenario $(+8 \%)$. There are cross-country differences in the effect with large population increases expected in both scenarios in Belgium, Cyprus, Ireland, Luxembourg and Sweden. Conversely, large decreases in the population are projected for both scenarios in Bulgaria, Lithuania and Latvia.

The EU projected total labor force (15-65 years of age), on the other hand, decreases in both scenarios (Table 5), though magnitudes differ substantially: about $-1 \%$ in the friendly scenario and about $-9 \%$ in the tough scenario. In the tough scenario, it decreases in all countries except Belgium, Cyprus, Luxembourg, Sweden and the UK. The projected decreases are more drastic for Eastern European countries (Estonia, Latvia, Lithuania, Poland, Romania and Bulgaria) as well as for Germany. A declining work force relative to the total population implies a growing scarcity of workers, which will put upward pressures on wage levels as depicted in Fig. 1. As the total population is projected to decrease only slightly or even to increase, depending on the scenario, domestic demand for goods and services is likely to change little or might even increase. This implies a minimal or even rightward shift in the $L D_{2010}$ curve in Fig. 1. Hence, declining labor force in both scenarios is likely to lead to structural problems as meeting this aggregate demand will become more challenging.

One key development is the ageing of the population. Figure 2 shows that the old-age dependency ratio, calculated as the number of people over 65 , divided by the size of the labor force, is set to increase in every country by 2030. The black solid bar, which represents the situation in 2010, shows that there is some heterogeneity in the old-age dependency ratio across the EU-27. It ranges from $18 \%$ in Ireland to $31 \%$ in Germany. The largest increases in this ratio are to be found in the countries with relatively lower old-age dependency ratios in 2010, such as Ireland, Slovakia, Cyprus, Poland and Malta. These countries can expect the share of old-age dependents to increase by more than 10 percentage points by 2030. Countries which already have large shares of old-age dependents, such as Belgium, Sweden and Greece can expect more modest increases. Overall, there seems to be some cross-country convergence in the old-age dependency ratio.

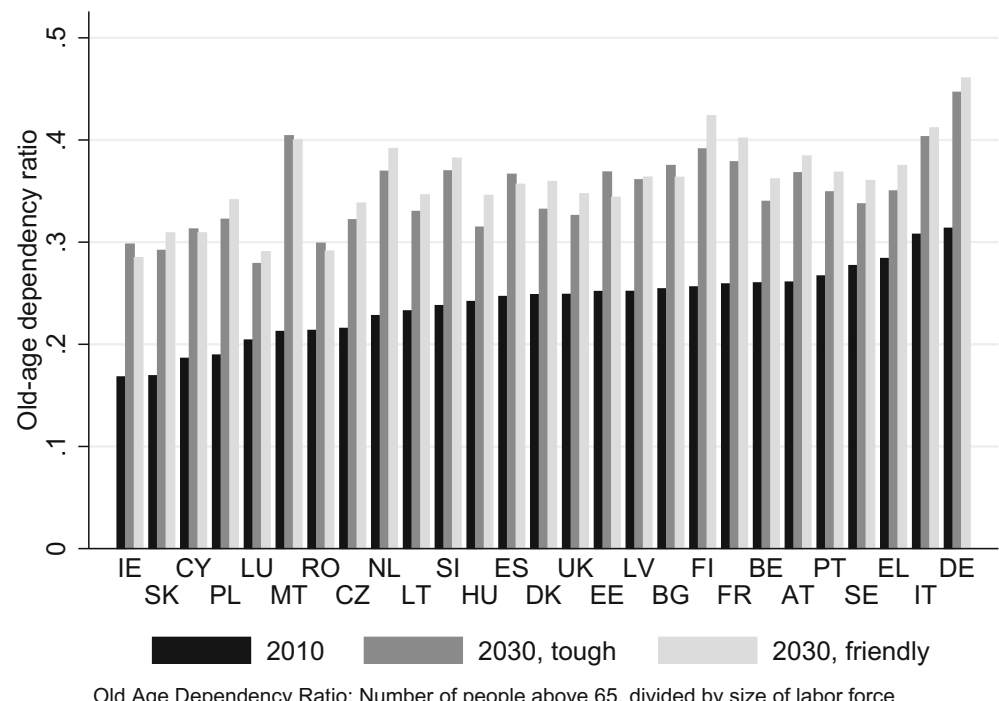

Fig. 2 Old-age dependency ratio. Source: Own calculations. Notes: Countries are ranked by their 2010 values in the ascending order 
Another important trend is the upskilling of the population in both scenarios (Table 6). The share of highly skilled individuals among the population aged 15-64 is projected to increase by 5-6 percentage points on average in the tough scenario and by about 11 percentage points in the friendly scenario, while the share of low skilled workers decreases by 5-8 percentage points on average, depending on the scenario. Germany, in the tough scenario, is the only case where essentially no upskilling is taking place. Changes in the share of medium skilled workers are more varied, decreasing more in the friendly scenario. These patterns are consistent across countries but especially pronounced in Cyprus, France, Lithuania and Poland.

\subsection{Effects on wages and labor supply}

The main insight from the previous subsection is that the workforce is ageing and becoming more skilled. This will affect real wage levels. First, as older (more educated) workers have higher wages than younger (less educated) workers, there is a direct positive effect of demographic change on average wages. Second, there will be wage changes due to labor demand (LD) and (further) labor supply (LS) adjustments to the new population structure. Taking these labor market responses into account, the high-skill premium can be expected to decrease. These developments could affect overall average wages in either direction.

Figure 3 shows projected changes in average real wages (i.e. measured in 2010 prices) in the tough and in the friendly scenario, distinguishing between the direct effect due to demographic change and the effect due to wage adjustment to demographic change. There is no clear correlation between the total change in the average wage (black bar) and the change in the size of the work force (dark gray bar), indicating that the composition of the projected workforce also plays an important role in determining wage reactions to population change. In both scenarios, the changes in average wage range from an increase of less than $5 \%$ in Hungary and Latvia to close to $20 \%$ in Germany, Spain and Austria. In most countries, the first round effect of demographic change, i.e. ageing and upskilling, drives most of the average wage change. However, countries such as Germany, Austria, the Netherlands, Finland, Estonia, Belgium, Sweden and Malta can also expect large average wage changes due to the behavioral response to these demographic changes.
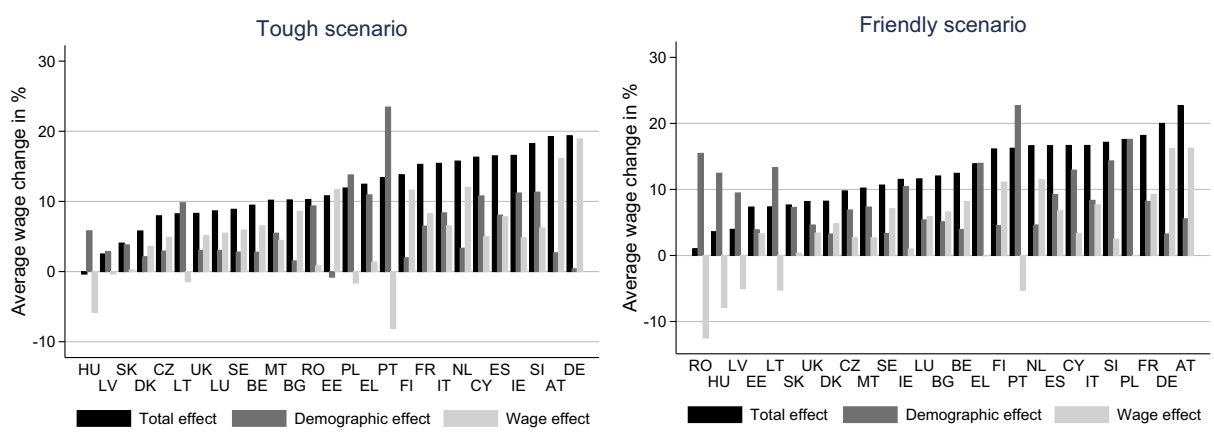

Fig. 3 Average wage changes due to demographic change and the labor market response. Note: Own calculations. The average wage change shows the change in average wages for workers between 2010 and 2030. This is decomposed into a demographic effect, which shows the effect of ageing, upskilling and other demographic changes on wages, ignoring the demand reaction, and a labor market effect which shows the effect of the labor supply shift on wages taking demand side elasticities into account 
Underlying employment changes are presented in Table 7, showing the share of people in the labor force working at least part-time in each scenario both before and after wage adjustments. Unlike with wages, it is not clear a priori how demographic changes affect employment levels directly before taking further labor market adjustments into account as older people tend to work less while more educated people tend to work more. Overall, we find rather small and positive changes in employment rates which are slightly higher after accounting for wage adjustments, meaning that the wage increases implied by labor shortages encourage more people (as a proportion of the active population) to work. This implies that, although the total size of the labor force decreases substantially in most countries (Table 5), the proportion of the labor force projected to work is, on average, stable and this is partly due to wage adjustment.

Table 8 shows the total number of labor hours supplied by country in 2010 and in the two 2030 scenarios, before and after wage adjustment. Total hours of work are projected to decrease substantially in most countries in the tough scenario. However, as the friendly scenario projects just a small decrease in the size of the labor force and a slight increase in employment rates, a slight increase in total hours of work is expected in this scenario. In both scenarios, most of the movement comes from demographic change with just small downward adjustments to average hours of work stemming from wage reactions.

\section{Effects on income distribution}

\subsection{Income changes}

We now turn our attention to the effect of demographic change and the accompanying wage adjustment on the income distribution, measured against a benchmark where tax-benefit policy parameters evolve in line with average market income. ${ }^{14}$ The increase in household original income between 2010 and 2030, which is due solely to demographic change, is denoted $\alpha_{d}^{1}$ (see Section 2.4), while the increase in household original income between 2010 and 2030 which is attributable to wage adjustment corresponds to $\alpha_{w}^{1}$. Table 9 shows the magnitude of these income growth rates between 2010 and 2030 by country.

With few exceptions, total income growth is positive between 2010 and 2030 (i.e. $\alpha=\alpha_{d} \alpha_{w}$ is greater than 1). We generally see an income decline due to demographic change $\left(\alpha_{d}<1\right)$, which is driven by the large increase in the over-64 population with little employment income. This dominates (direct) wage changes due to the increasing share of older workers and upskilling. This effect is counteracted by strong income growth due to wage adjustment $\left(\alpha_{w}>1\right)$. There is a quite distinctive grouping of countries along regions/welfare typologies. It is primarily Central and Eastern European (CEE) countries (together with Germany and Austria) which show the largest decrease in average original income due to demographics $\left(\alpha_{d}\right)$, while Southern European countries (Portugal, Italy and Greece) and Ireland exhibit the largest increases. ${ }^{15}$ The income growth rate due to wage adjustment is highest in Austria, Germany, Ireland, the Netherlands, Slovenia and the UK. This can be mostly explained by higher average wages, resulting, among other things, from

\footnotetext{
${ }^{14}$ Using a benchmark where tax-benefit policy parameters are fixed in real terms does not alter our conclusions. Results are available upon request.

${ }^{15}$ Note also that countries which have been hit harder in the Great Recession tend to have the highest $\alpha_{d}$. This could imply that favorable (or less dramatic) demographic projections will allow them to catch up with other countries to some extent.
} 
relatively modest upskilling and thus lower downward pressure on wages of high-skilled workers.

Hungary, Latvia and Malta, in turn, exhibit the most negative income changes. For Hungary and Latvia, this phenomenon can be explained by the projected negative trend in average wages due to the projected change in the skill composition. Malta, in turn, features the largest share of low-skilled workers, who realize modest income increases as the skill composition changes. Other skill groups, in contrast, partly exhibit strongly negative income changes, resulting in an overall negative effect.

\subsection{Impact on inequality and poverty}

The projected impacts of demographic change on income inequality, is presented in Table 2 for the EU-27 as a whole. On average, European Gini coefficients are projected to remain almost constant in both population scenarios between 2010 and 2030. Demographic change tends to increase inequality. Higher average wages, however, work in the opposite direct direction, counteracting this increase to a large extent. This mechanism can be observed for most inequality measures investigated.

Figure 4 presents country-wise changes of the Gini coefficient. Detailed results are provided in Table 10 in the Online Appendix. Complementary analyzes for the P90/50 ratio (which compares the $90^{\text {th }}$ decile of income to the $50^{\text {th }}$ ) and the P10/50 ratio (which compares the $10^{\text {th }}$ decile of income to the $50^{t h}$ ) can be found in Tables 11 and 12 in the Online Appendix, leading to similar quantitative conclusions. The circles in Fig. 4 represent the baseline levels of income inequality in 2010. The projected levels for 2030 before wage adjustment are indicated by a cross and, after wage adjustment, by a diamond.

Considering the total effect of demographic change on the Gini coefficient of disposable income, the most affected countries are Denmark, Finland, Sweden, Romania and Slovakia. In the case of Denmark, Finland, Sweden and Slovakia, inequality is projected to increase due to a combination of demographic change and wage reactions. Conversely, Romania can expect inequality to decrease for the same reason. This trend is confirmed in Table 11, which decomposes the ratio of the 90th percentile of income to the 50th. This indicates that much of the movement observed in the Gini index is due to increases (in the Nordic countries and Slovakia) and decreases (in Romania) in inequality at the top of the income distribution. Looking lastly at the detailed decomposition of the ratio of the 10th percentile of income to

Table 2 Effects on inequality and poverty in the EU-27

\begin{tabular}{lrrrrrrr}
\hline & \multicolumn{2}{l}{ Tough Scenario } & & \multicolumn{2}{l}{ Friendly Scenario } \\
\cline { 2 - 3 } & Total & Demographic effect & Wage effect & Total & Demographic effect & Wage Effect \\
\hline Gini coefficient & $0.0 \%$ & $2.1 \%$ & $-2.1 \%$ & & $-0.1 \%$ & $1.7 \%$ & $-1.8 \%$ \\
P90/50 ratio & $-0.5 \%$ & $1.7 \%$ & $-2.2 \%$ & & $-0.1 \%$ & $-1.9 \%$ & $-1.9 \%$ \\
P10/50 ratio & $-1.0 \%$ & $-0.9 \%$ & $-0.1 \%$ & & $0.0 \%$ & $-0.1 \%$ & $0.1 \%$ \\
Poverty Headcount & $2.1 \%$ & $2.4 \%$ & $-0.4 \%$ & & $-0.4 \%$ & $0.9 \%$ & $-1.4 \%$ \\
Poverty Gap & $1.4 \%$ & $4.1 \%$ & $-2.7 \%$ & & $-2.6 \%$ & $1.1 \%$ & $-3.7 \%$ \\
\hline
\end{tabular}

The table shows population-weighted means for the respective index change for the EU-27 from 2010 to 2030. The total effect is decomposed into a demography-induced part (mainly upskilling and ageing) and a part that captures the labor market response due to a change in the relative supply of skill groups. Countryspecific figures can be found Tables 10 to 14 in the Online Appendix 

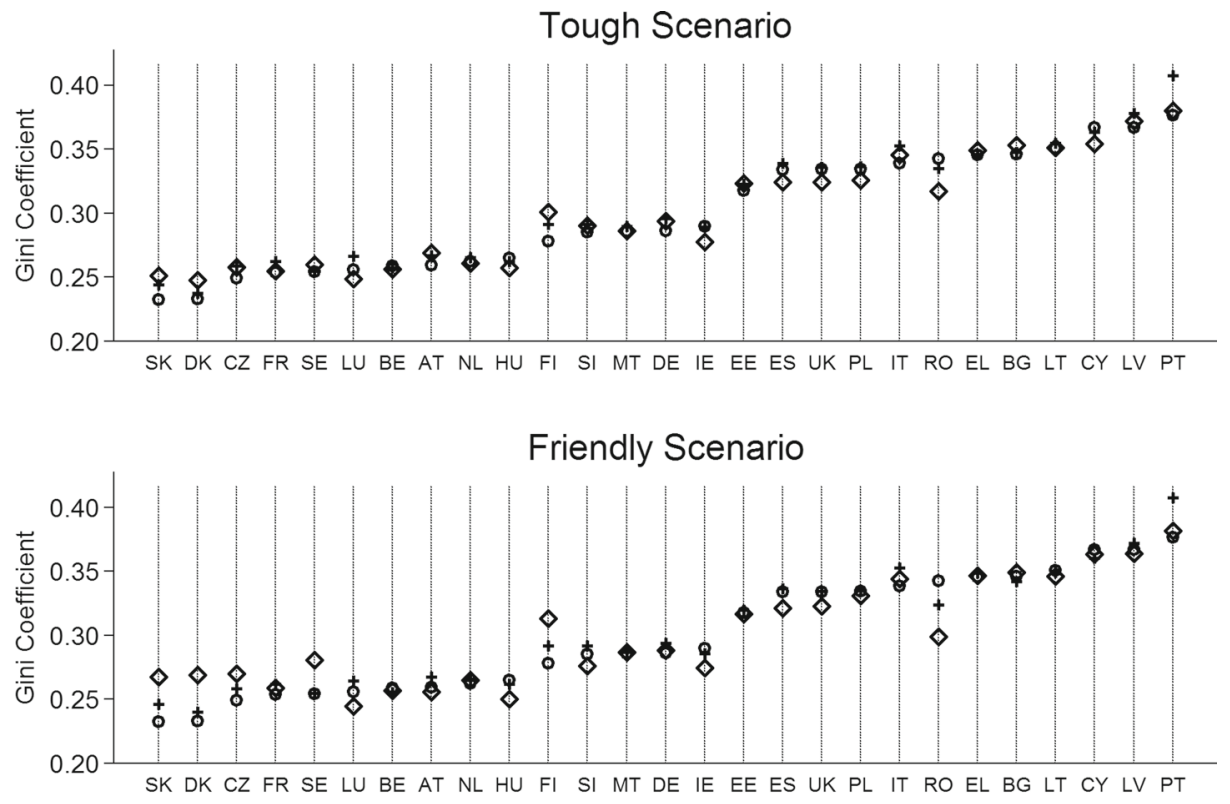

\section{- 2010 + 2030, demographic effect $\diamond 2030$, demographic + wage effect}

Fig. 4 Projected inequality levels between 2010 and 2030 across the EU. Note: Own calculations using EUROMOD linked to EU-SILC data reweighted to 2030 and adjusted for wage reactions to demographic change. Gini coefficients calculated using equivalized disposable household income. Graphs are sorted in ascending order by inequality levels in 2010. The underlying figures can be found in Table 10 in the Online Appendix

the 50th in Table 11, we observe that some of the countries with small changes in the Gini index are actually projected to have large increases/decreases in inequality at the bottom of the income distribution. Increases in inequality at the bottom of the income distribution are projected for Portugal, the Netherlands, Italy and Romania while decreases are noted for Spain, Malta and Slovakia.

The projected changes in poverty headcounts by country, defined as equivalised household disposable income of less than $60 \%$ of median income, are visualized in Fig. 5 and detailed in Table 13. Poverty headcount are projected to slightly increase (decrease) in the tough (friendly) population scenario. These changes are modest, rarely exceeding 5 percentage points where the baseline average is $16 \%$. Unlike inequality, these effects are driven by two reinforcing effects in both scenarios. On average, both demographic and wage adjustments increase poverty in the tough scenario and decrease it in the friendly scenario.

A couple of country cases deserve a closer look. We project substantial rises in relative poverty for Ireland and Portugal in both scenarios. In Ireland, this increase is driven purely by demographic change while, in Portugal, the increase is due to a combination of demographic change and wage adjustment. We examine projections for the poverty gap, which goes beyond the headcount index by weighting very low incomes higher than incomes just below the poverty threshold (Table 14). The poverty gap is actually projected to decrease in Ireland, despite an increasing poverty headcount, suggesting that a higher number of households find themselves just below the poverty line in 2030, but not far below. The poverty 

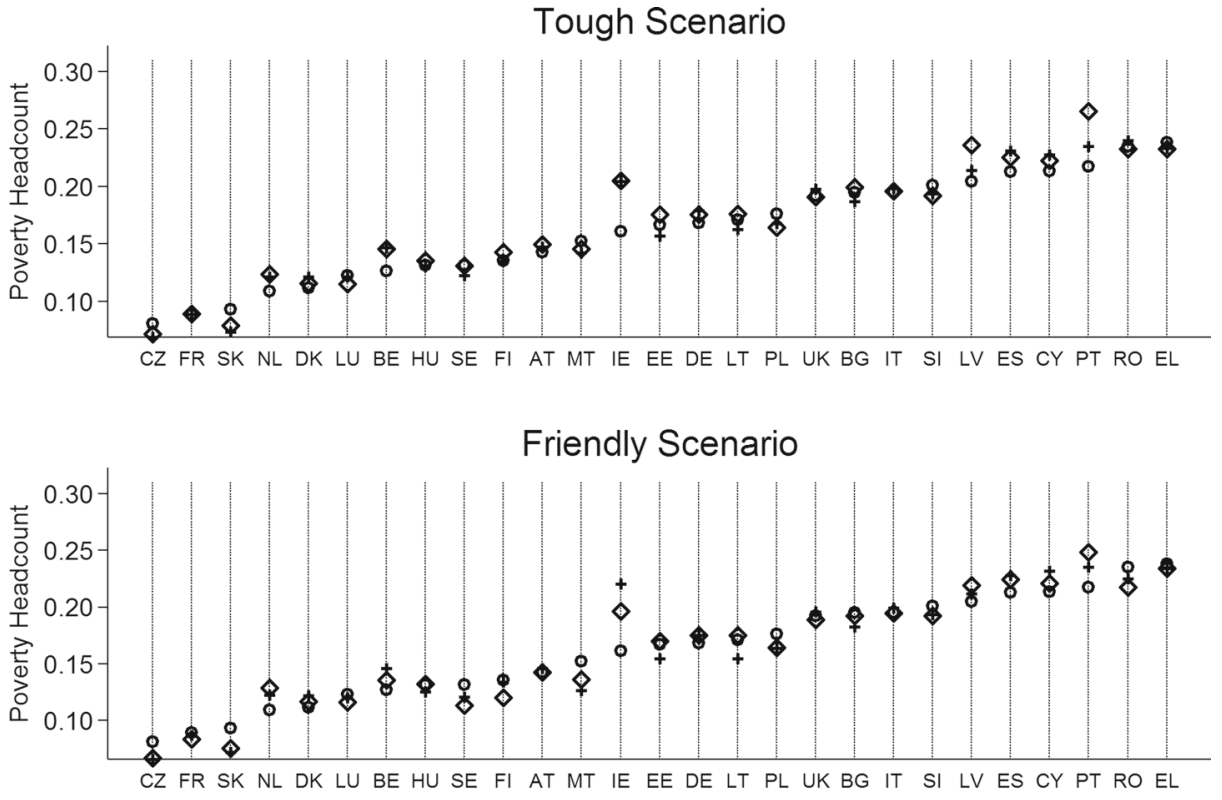

\section{- 2010 + 2030, demographic effect}

\section{0, demographic + wage effect}

Fig. 5 Projected poverty headcounts between 2010 and 2030 across the EU. Note: Own calculations using EUROMOD linked to EU-SILC data reweighted to 2030 and adjusted for wage reactions to demographic change. Graphs are sorted in ascending order by poverty headcount levels in 2010. The underlying figures can be found in Table 13 in the Online Appendix

headcount increase for Ireland should be interpreted with this in mind. Portugal, in contrast, shows a strong increase in the poverty gap as well as the poverty headcount, creating by far the most worrying country case in the EU-27. Apart from these outliers, relative poverty is projected to undergo marginal changes in most countries.

As a caveat, our approach is not able to account for changing old-age pension claims as a consequence of changing wage trajectories over the life cycle. This would require a dynamic modelling of individual earnings profiles, along with the full set of institutional rules of the respective pension system, ideally also capturing interactions with private and occupational pension schemes. In light of increasing average wages (Table 3), it is fair to assume higher pension claims in 2030. Low- and medium-skilled workers will profit in particular from this, as those groups are becoming more scarce in the future, experiencing more positive wage changes. For this reason, our results might suffer from underestimating the incomes of pensioners. Accounting for different pension claims is hence likely to lead to overall lower projected measures of poverty and inequality.

\subsection{Secular rise in employment of older workers}

From 2000 to 2016, labor force participation rates of EU workers between 50 and 74 years increased from $34.7 \%$ to $45.5 \%$ (men) and from $26.8 \%$ to $40.0 \%$ (women), respectively, with no indication of a general slowing down. If this trend reflects genuine changes in labor supply behavior rather than a mechanical increase from upskilling, our approach does not to 


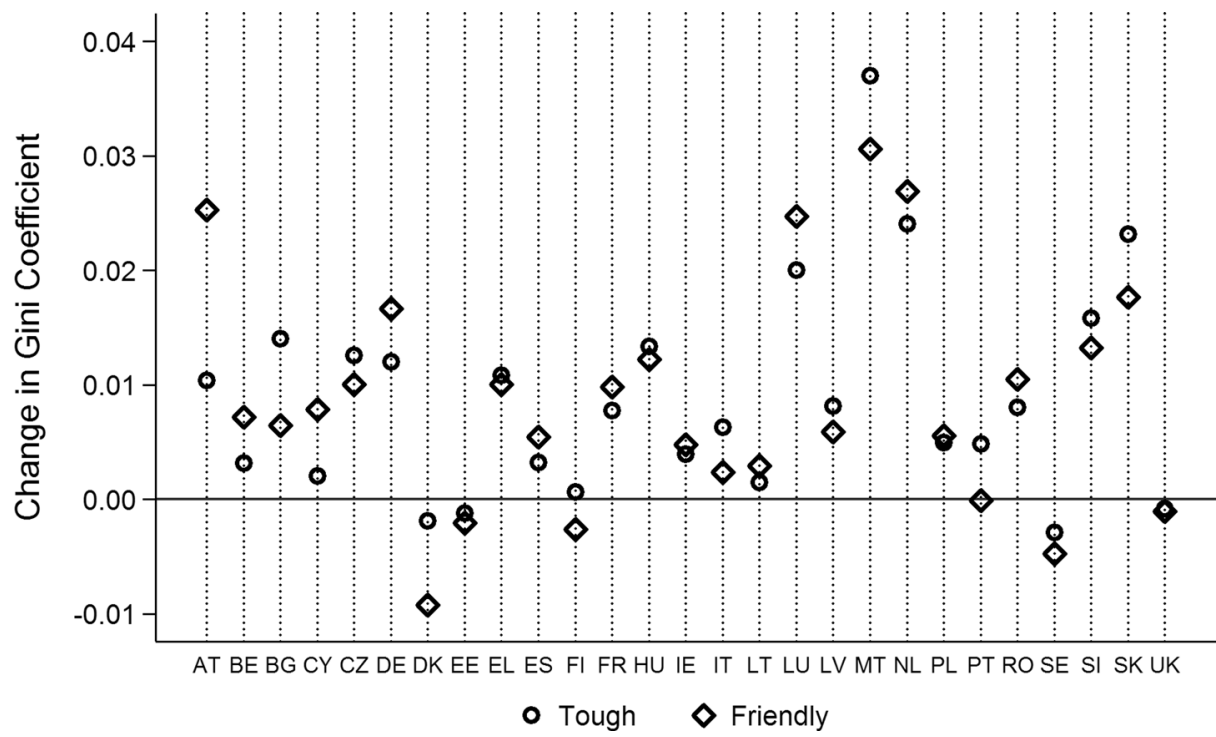

Fig. 6 Change in Gini Coefficient from secular rise in Employment. Notes: The figure shows the change in the Gini coefficient of disposable incomes from the anticipated secular increase in labor force participation, compared to the baseline results (Fig. 4)

capture these changes. We therefore consider also income inequality in 2030 by additionally assuming a continuation of this secular rise in employment. We use historic time trends in employment rates from 2000 to 2016 from Eurostat (by age group, sex and skill group) to predict new age, gender, country and skill specific employment rates for those aged 50-70 in the year 2030. We regress the employment rate on the year, with the full set interactions of country groups and skill fixed effects. We allow for differential time trends by sex and age group (50-55, 56-60, 61-64, 65-70 years) by estimating these models separately. Estimation results are shown in Table 15 in the Online Appendix. After reweighting the EU-SILC data to take account of demographic change between 2010 and 2030, we then predict a new employment rate for those aged 50-70. The LS-LD model is applied to this new reweighted population in order to calculate new equilibrium employment and wage rates. ${ }^{16}$

The results are presented in Fig. 6 for the Gini coefficient and Fig. 7 for the poverty headcount. These show the change in each measure, compared to the baseline results presented in Figs. 4 and 5. With few exceptions, the secular increase in labor force participation leads to higher income inequality, mostly in the range of 1 to 2 Gini points. This result is as expected as older workers tend to earn more than younger workers.

On average, relative poverty is less affected by the increase in elderly employment. However, a significant decrease in poverty can be expected in Ireland which actually works to counteract the 4-5 point increase in the poverty headcount predicted in the baseline scenario (without secular increases to elderly employment). This hints to pensioners ending up just below the poverty line being the driving force for the projected rise in poverty in Ireland.

\footnotetext{
${ }^{16}$ This procedure will overestimate future employment rates for older workers if the time trend slows down between 2016 and 2030 .
} 


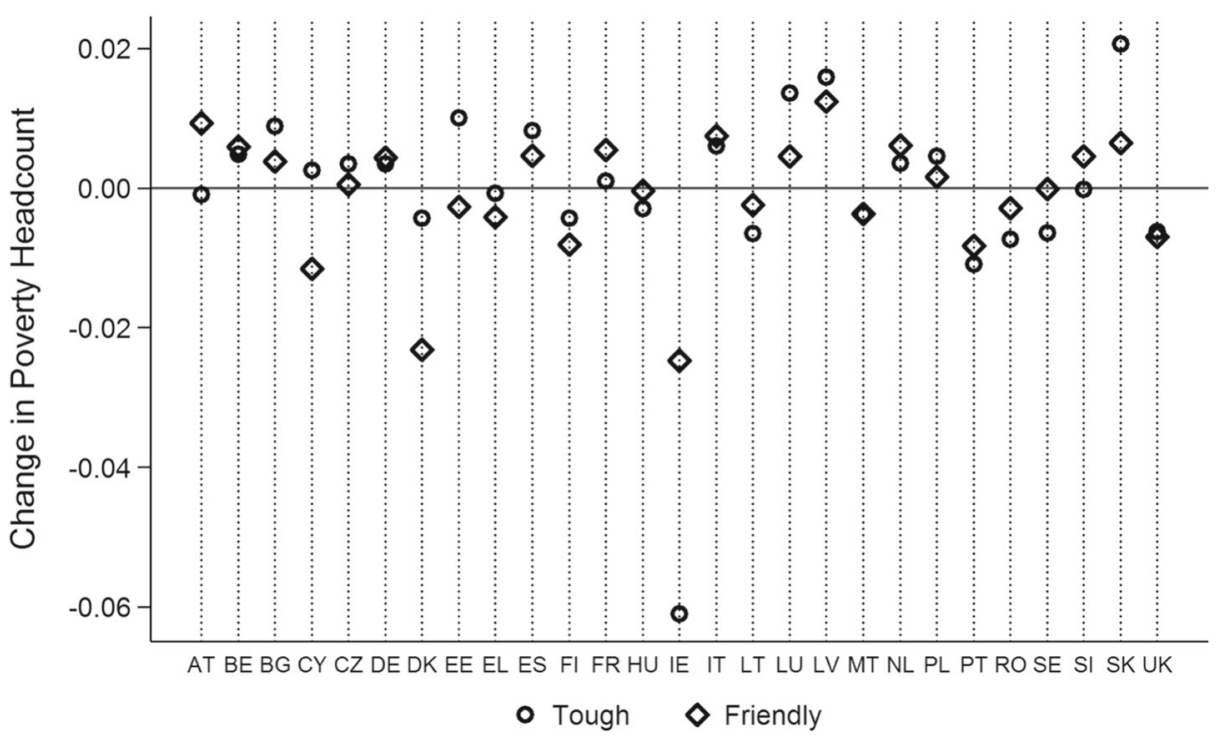

Fig. 7 Change in Poverty Headcount from secular rise in Employment. Notes: The figure shows the change in the poverty headcount from the anticipated secular increase in labor force participation, compared to the baseline results (Fig. 5)

\section{The stabilizing capability of European tax-benefit systems}

The ability of European tax-benefit systems to stabilise income has been studied by Dolls et al. (2012) who found that stabilisation of disposable incomes ranged from 25 per cent to 56 per cent of the overall change in market incomes. Stabilisation of income inequality has also been studied and found to differ substantially from stabilisation of income (Callan et al. 2018; Paulus and Tasseva 2018). In this section, we consider the inequality stabilization and redistributive capabilities of each of the tax-benefit systems in the EU-27. To this end, Fig. 8 contrasts changes in market income inequality, measured by the Gini coefficient with changes in disposable income inequality between 2010 and 2030. Several important findings emerge from this.

First, demographic changes alone (i.e. with constant wages) almost universally increase market income inequality both in the tough and in the friendly scenario, as the theoretical literature on population ageing generally predicts. Inequality increasing effects are largest (up to 5 percentage points) in larger economies (France, Germany, Spain, Italy) together with Austria, Finland and Slovenia. The UK and Ireland are on the other side of the scale with almost no changes in demography-induced market income inequality.

Second, disposable income inequality, in contrast, increases much less or even decreases, indicating tax-benefit systems' built-in capacity to absorb some of the 'raw' inequality increase. This is characteristic of all countries except for Portugal, where, basically, all changes in market income inequality translate into disposable income inequality. This is due to the fact that, unlike most other countries, demographic change decreases the share of low-income recipients in Portugal; the increase in inequality hence reflects an 
(a) Tough Scenario (constant wage)

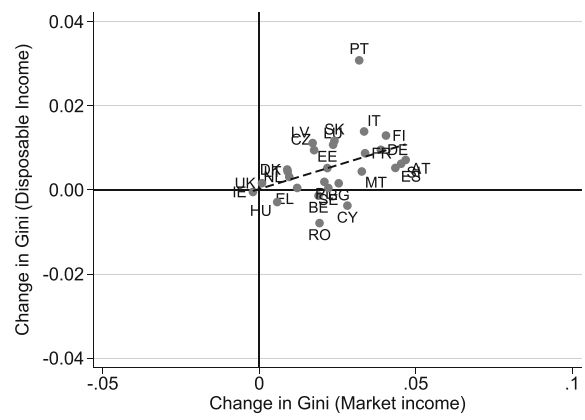

(c) Tough Scenario (with wage changes)

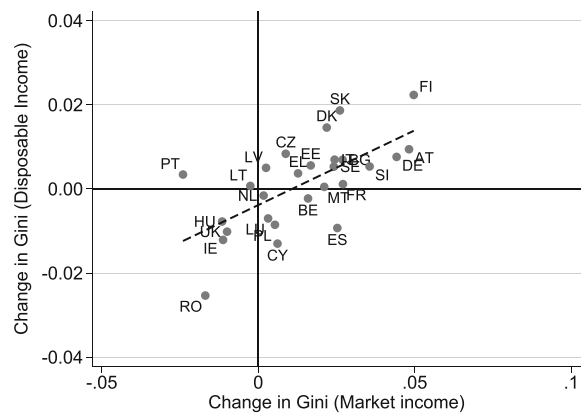

(b) Friendly Scenario (constant wage)

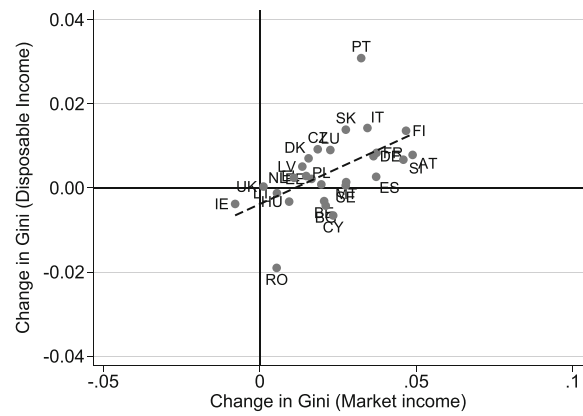

(d) Friendly Scenario (with wage changes)

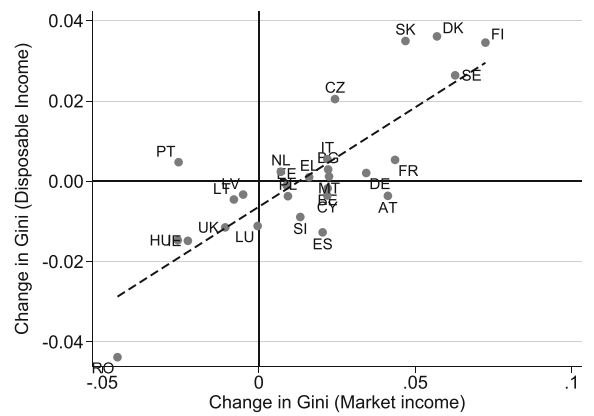

Fig. 8 Changes in the Gini coefficient for market and disposable income. Note: Own calculations using EUROMOD linked to EU-SILC data for 2010, reweighted to 2030 and adjusted for wage reactions to demographic change. The dashed line represents the linear fit

overall income increase (see also Table 9). ${ }^{17}$ In relative terms, Spain and Cyprus seem better equipped to withstand increases in market income inequality in either demographic scenario.

Third, when taking into account wage adjustments, we find more heterogeneous outcomes in both market and disposable income inequality, with a substantial share of countries now displaying a decline in the Gini for market income. Finland, Denmark and Slovakia are found among the countries with the least redistributive capacity in both scenarios.

\section{Conclusions}

Given their tremendous impact on society, demographic changes are among the most important policy challenges in the European Union. Population projections suggest that ageing and shrinking labor forces will have important implications, not only for fiscal revenue and social security systems, but also for the income distribution. While the effect of a growing

\footnotetext{
${ }^{17}$ This is likely to be due to the increasing educational attainment of the Portuguese labor force. Portugal is among the countries with the highest initial share of low-skilled workers $(67 \%)$, which is projected to decrease by 14 percentage points.
} 
dependency ratio on fiscal sustainability, in particular with regard to the financing of European welfare states, has been addressed by some contributions in the literature (Dolls et al. 2017), very little is known about its effect on the income distribution.

This paper is the first attempt to fill this gap. Theory predicts that population ageing increases income inequality in the population as a whole due to, among other things, increasingly divergent human capital and lower income towards the end of the life course. By contrast, the effect of upskilling on income inequality is ambiguous. We investigate the ability of tax-benefit systems to stabilize these expected changes. We apply a decomposition approach that enables us to separate the pure demographic effect from resulting labor market effects on the income distribution in Europe in the year 2030.

We rely on detailed population projections for two different scenarios, 'tough' and 'friendly', containing joint distributions of age, sex, level of urbanization and educational attainment as well as household structure. The scenarios can be interpreted as upper and lower bounds for the severity of demographic change. We take the population projections to our harmonized European micro data by applying a reweighting procedure. Our partial labor market model, linking the resulting labor supply and demand responses, provides us with new wage and employment changes leading to a new labor market equilibrium in each member state. Implementing these steps sequentially, we are able to isolate the effect of demographic change from the accompanying effect of wage adjustments.

Our analysis shows that the EU-27 average income inequality, measured by the Gini coefficient, is projected to increase by 1-2 per cent due to demographic change. Our results suggest that accompanying wage adjustments partly offset the increased inequality. Notable increases in inequality are found for Scandinavian countries in particular, which may lead to cross-country convergence in income inequality. Examining other measures of inequality, we find that most of the increase is projected to occur in the top half of the income distribution, whereas income inequality in the bottom half of the income distribution is projected to undergo only marginal changes. Results are more ambiguous for relative poverty, which is projected to increase in the tough scenario but slightly decrease in the friendly scenario. In general, projected changes in relative poverty are small but there are some country exceptions such as Ireland and Portugal.

In an additional analysis, we account for a secular rise in the employment that has been observed for workers older than 50 years. If this trend is going to continue, one can expect an additional increase in disposable income inequality of one to two Gini points for most EU countries, Scandinavian countries and the UK being the exception. Poverty headcounts, in contrast, are projected to experience only marginal additional changes. This suggests a non-negligible inequality impact from reforms aiming at higher labor force participation of older workers, such as raising the statutory retirement age.

Two important general messages emerge. First, the challenges countries face vary and not all will be exposed to a considerable increase in market income inequality. However, among those who will, there are some tax-benefit systems better equipped to moderate such increases than others. Second, tax-benefit systems cushion some of the increases in market income inequality so that the increase in disposable income inequality is smaller. Our paper shows that the size of these cushioning effects to a large extent depends on whether we consider the (direct) demographic effect only or also the resulting wage changes. This highlights the importance of accounting for labor market adjustments in an analysis such as the present one.

Acknowledgements This paper is funded by the EU FP7 project 'Employment 2025: How will multiple transitions affect the European labour market (NEUJOBS)' (under grant agreement 266833) and Economic 
and Social Research Council (ESRC) through the Research Centre on Micro-Social Change (MiSoC) at the University of Essex, grant number ES/L009153/1. The process of extending and updating EUROMOD is financially supported by the European Commission [Progress grant no. VS/2011/0445] and we would like to thank all past and current members of the EUROMOD consortium. We use microdata from the EU Statistics on Incomes and Living Conditions (EU-SILC) made available by Eurostat under contract EU-SILC/2011/55 and (for the UK) the Family Resources Survey data made available by the Department of Work and Pensions via the UK Data Archive. The authors alone are responsible for the analysis and interpretation of the data reported here.

Open Access This article is distributed under the terms of the Creative Commons Attribution 4.0 International License (http://creativecommons.org/licenses/by/4.0/), which permits unrestricted use, distribution, and reproduction in any medium, provided you give appropriate credit to the original author(s) and the source, provide a link to the Creative Commons license, and indicate if changes were made.

\section{References}

Atkinson, A.B., Bourguignon, F.: Introduction: income distribution today. In: Atkinson, A.B., Bourguignon, F. (eds.) Handbook of Income Distribution, vol 2A of Handbook of Income Distribution, pp. xvii- 1xiv. Elsevier, Amsterdam (2015)

Aziz, O.A., Ball, C., Creedy, J.: The distributional impact of population ageing in New Zealand. N. Z. Econ. Pap. 49(3), 207-226 (2015)

Bargain, O.: Decomposition analysis of distributive policies using behavioural simulations. Int. Tax Public Financ. 19(5), 708-731 (2012a)

Bargain, O.: The distributional effects of tax-benefit policies under New Labour: a decomposition approach. Oxf. Bull. Econ. Stat. 74(6), 856-874 (2012b)

Bargain, O., Callan, T.: Analysing the effects of tax-benefit reforms on income distribution: a decomposition approach. J. Econ. Inequal. 8(1), 1-21 (2010)

Bargain, O., Callan, T., Doorley, K., Keane, C.: Changes in income distributions and the role of tax-benefit policy during the Great Recession: an international perspective. Fisc. Stud. 38(4), 559-585 (2017)

Bargain, O., Dolls, M., Immervoll, H., Neumann, D., Peichl, A., Pestel, N.: Tax policy and income inequality in the U.S., 1979-2007: A decomposition approach. Econ. Inq. 53(2), 1061-1085 (2015)

Bargain, O., Orsini, K., Peichl, A.: Comparing labor supply elasticities in Europe and the US: new results. J. Hum. Resour. 49(3), 723-838 (2014)

Bourguignon, F., Spadaro, A.: Microsimulation as a tool for evaluating redistribution policies. J. Econ. Inequal. 4(1), 77-106 (2006)

Cai, L., Creedy, J., Kalb, G.: Accounting for population ageing in tax microsimulation modelling by survey reweighting. Aust. Econ. Pap. 45(1), 18-37 (2006)

Callan, T., Doorley, K., Savage, M.: Inequality in EU Crisis Countries. How Effective were Automatic Stabilisers? EUROMOD Working Paper EM 10/18. University of Essex, Colchester (2018)

CEDEFOP: Future skills supply and demand in Europe: Forecast 2012, European Centre for the Development of Vocational Training Research Paper No. 26 (2012)

Deaton, A.C.P.: The effects of economic and population growth on national saving and inequality. Demography 34(1), 97-114 (1997)

Deville, J.-F., Särndal, C.-E.: Calibration estimators in survey sampling. J. Am. Stat. Assoc. 87, 376-382 (1992)

DiNardo, J., Fortin, N., Lemieux, N.: Labor market institutions and the distribution of wages, 1973-1992: a semiparametric approach. Econometrica 64, 1001-1044 (1996)

Dolls, M., Doorley, K., Paulus, A., Schneider, H., Siegloch, S., Sommer, E.: Fiscal sustainability and the demographic transition: a micro approach for 27 EU countries. Int. Tax Public Financ. 24(4), 575-615 (2017)

Dolls, M., Fuest, C., Peichl, A.: Automatic Stabilizers and Economic Crisis: US vs. Europe. J. Public Econ. 96(3-4), 279-294 (2012)

Edwards, R., Lange, F.: The US labor market in 2030: a scenario based on current trends in supply and demand, IZA Discussion Paper No. 7825 (2013)

ESPON \& NIDI: Demographic and Migratory Flows affecting European Regions and Cities, Final report DEMIFER project (2010)

European Commission: Europe 2020: a strategy for smart, sustainable and inclusive growth, European Union (2010) 
European Commission: The 2012 ageing report - economic and budgetary projections for the 27 EU Member States (2010-2060). Eur. Econ. 2, 2012 (2012)

Figari, F., Paulus, A., Sutherland, H., Tsakloglou, P., Verbist, G., Zantomio, F.: Removing homeownership bias in taxation: The distributional effects of including net imputed rent in taxable income. Fisc. Stud. 38(4), 525-557 (2017)

Förster, M.F., Tóth, I.G.: Cross-country evidence of the multiple causes of inequality changes in the OECD area. In: Atkinson, A.B., Bourguignon, F. (eds.) Handbook of Income Distribution, vol. 2B of Handbook of Income Distribution, pp. 1729-1843. Elsevier, Amsterdam (2015)

Hills, J., Paulus, A., Sutherland, H., Tasseva, I.: Policy and poverty in seven EU-Countries in the Lisbon decade: the contribution of tax-benefit policy changes. In: Cantillon, B., Goedemé, T., Hills, J. (eds.) Improving Poverty Reduction in Europe, Oxford University Press (2019)

Huisman, C., de Beer, J., van der Erf, R., Gaag, v.an.d.er., N., Kupiszewska, D.: Demographic scenarios 2010-2030, NEUJOBS Working Paper, D10.1 (2013)

Immervoll, H.: Falling up the stairs: the effects of 'bracket creep' on household incomes. Rev. Income Wealth 51(1), 37-62 (2005)

Immervoll, H., Levy, H., Lietz, C., Mantovani, D., Sutherland, H.: The sensitivity of poverty rates to macrolevel changes in the European Union. Cambridge Journal of Economics 30(2), 181-199 (2006)

KC, S., Barakat, B., Goujon, A., Skirbekk, V., Sanderson, W., Lutz, W.: Projection of populations by level of educational attainment, age, and sex for 120 countries for 2005-2050. Demogr. Res. 22, 383-472 (2010)

Lichter, A., Peichl, A., Siegloch, S.: The own-wage elasticity of labor demand: a meta-regression analysis. Eur. Econ. Rev. 80, 94-119 (2015)

OECD: OECD employment outlook. OECD Publishing, Paris (2014)

Paulus, A., Figari, F., Sutherland, H.: The design of fiscal consolidation measures in the European Union: distributional effects and implications for macro-economic recovery. Oxf. Econ. Pap. 69(3), 632-654 (2017)

Paulus, A., Tasseva, I.: Europe through the crisis: discretionary policy changes and automatic stabilisers EUROMOD Working Paper EM 16/18. University of Essex, Colchester (2018)

Sutherland, H., Figari, F.: EUROMOD: the European Union tax-benefit microsimulation model. Int. J. Microsimulation 6(1), 4-26 (2013)

Tóth, I.G.: Revisiting grand narratives of growing inequalities: lessons from 30 country studies. In: Nolan, B., Salverda, W., Checchi, D., Marx, I., McKnight, A., Tóth, I.G., van de Werfhorst, H.G. (eds.) Changing inequalities and societal impacts in rich countries: thirty countries' experiences, pp. 11-48. Oxford University Press, Oxford (2014)

von Weizsäcker, R.K.: Age structure and income distribution policy. J. Popul. Econ. 1(1), 33-55 (1988)

von Weizsäcker, R.K.: Public pension reform, demographics, and inequality. J. Popul. Econ. 8(2), 205-221 (1995)

von Weizsäcker, R.K.: Distributive implications of an aging society. Eur. Econ. Rev. 40(3-5), 729-746 (1996)

Publisher's note Springer Nature remains neutral with regard to jurisdictional claims in published maps and institutional affiliations. 